Estimativa do balanço de radiação por sensoriamento remoto de diferentes usos de solo no sudoeste da Amazônia brasileira Luiz Carlos Silva, José Maurício Cunha, Nadja Gomes Machado, Milton César Costa Campos, Marcelo Sacardi Biudes

\title{
ESTIMATIVA DO BALANÇO DE RADIAÇÃO POR SENSORIAMENTO REMOTO DE DIFERENTES USOS DE SOLO NO SUDOESTE DA AMAZÔNIA BRASILEIRA
}

\section{Estimative of radiation balance by remote sensing of different soil uses in the brazilian southern Amazon}

Luiz Carlos Silva

Universidade Federal do Amazonas do Instituto de Educação, Agricultura e Ambiente, Humaita,

Amazonas, Brasil

luiz_silva03@yahoo.com.br

José Maurício Cunha

Universidade Federal do Amazonas do Instituto de Educação, Agricultura e Ambiente, Humaita,

Amazonas, Brasil

maujmc@gmail.com

Nadja Gomes Machado

Universidade Federal do Mato Grosso, Cuiabá, Mato Grosso, Brasil nadja.machado@blv.ifmt.edu.br

Milton César Costa Campos

Universidade Federal do Amazonas do Instituto de Educação, Agricultura e Ambiente, Humaita,

Amazonas, Brasil

mcesarsolos@gmail.com

Marcelo Sacardi Biudes

Universidade Federal do Mato Grosso, Cuiabá, Mato Grosso, Brasil marcelo.biudes@gmail.com

Artigo recebido em 01/11/2014 e aceito para publicação em 21/09/2015

RESUMO: Mudanças no uso do solo têm motivado pesquisas sobre a dinâmica de trocas radiativas e energéticas na Amazônia Brasileira que, por sua vez, geram demanda destas informações de superfície em escalas espaciais e temporais. Enquanto a medição destas trocas em torres micrometeorológicas fornece resultados pontuais, o sensoriamento remoto apresenta resultados acurados e de baixo custo para estimá-las em escala regional. Este estudo objetivou avaliar a distribuição espacial e temporal de estimativas de saldo de radiação e parâmetros biofísicos por sensoriamento remoto de diferentes usos do solo no sudoeste da Amazônia Brasileira. Foram selecionadas 04 áreas de solo coberto por floresta amazônica natural, floresta amazônica manejada, sistema silvipastoril e pastagem. O saldo de radiação, NDVI, índice de área foliar, albedo e temperatura radiométrica foram estimados pelo algoritmo SEBAL, usando imagens do sensor 
TM do satélite Landsat 5 em julho de 2009, 2010 e 2011. O NDVI, IAF, albedo e saldo de radiação apresentaram maiores valores na floresta natural, seguida por floresta manejada, sistema silvipastoril e pastagem. A temperatura radiométrica da superfície apresentou maiores valores para o sistema silvipastoril seguido por pastagem, floresta natural e floresta manejada.

Palavras-chave: Floresta Amazônica. Sistema Silvipastoril. Pastagem. Variáveis Biofísicas. SEBAL.

ABSTRACT: Changes in land use have motivated research on the dynamics of radiative and energy exchange in the Brazilian Amazon, which in turn cause demand for such data on the surface in spatial and temporal scales. While measuring these changes in micrometeorological towers provides punctual results, remote sensing provides accurate and low cost results to estimate them on a regional scale. This study aimed to evaluate the spatial and temporal distribution of estimates of net radiation and biophysical parameters from remote sensing in different land uses in southwestern Brazilian Amazon. Four sites were selected with soil covers by natural Amazon forest, Amazon managed forest, pasture and silvopastoral system. The net radiation and biophysical parameters (NDVI, leaf area index, albedo and radiometric temperature) were estimated by the SEBAL algorithm, using images from the Landsat TM sensor 5 in July of 2009, 2010 and 2011. The NDVI, LAI, albedo and net radiation were higher in natural forest, followed by managed forest, grassland and silvopastoral system. Radiometric surface temperature were higher in the silvopastoral system followed by pasture, natural forest and managed forest.

Keywords: Amazon Rainforest. Silvopastoral System. Pasture. Biophysical Variables. SEBAL.

\section{INTRODUÇÃO}

As características biofísicas das superfícies determinam a distribuição das trocas energéticas, regimes térmicos do solo (GOMES et al., 2013), fotossíntese e evaporação da água, e a quantidade é determinada pela energia disponível definida como o saldo dessas trocas radiativas de ondas curtas e longas. Esses processos radiativos na superfície interferem significativamente na redistribuição de umidade $\mathrm{e}$ calor no solo e na atmosfera que, por sua vez, afetam o comportamento do tempo, clima e biosfera na Terra (BASTIAANSSEN et al., 1998; ROERINK et al., 2000).

Saliente-se que, pesquisas com intuito de compreender a dinâmica espacial e temporal das trocas radiativas e energéticas têm sido motivadas na bacia Amazônica por causa das mudanças no uso e cobertura do solo (LIBERATO, 2011), o que tem provocado um aumento na demanda por dados de processos radiativos e energéticos na superfície em largas escalas espaciais e temporais. A medição dessas trocas em torres micrometeorológicas fornecem resultados pontuais, representativos de pequenas áreas homogêneas, não sendo adequados quando o objetivo é a escala regional (MACHADO et al., 2014).
Nesse sentido, técnicas de sensoriamento remoto têm se mostrado como uma alternativa com boa acerácea e baixo custo para estimativa das trocas radiativas e energéticas na superfície em escala regional (MACHADO et al., 2014). Portanto, essas técnicas permitem monitorar em escala regional o particionamento de energia e os ciclos de carbono e água com baixos custos operacionais e maior aquisição de dados espaciais e temporais (COURAULT et al., 2005; ALLEN et al., 2011), o que a torna uma poderosa ferramenta para obtenção de informações sobre manejo de recursos naturais, tais como água, solo e vegetação (BRAGA et al., 2009).

Um dos proeminentes algoritmos usados no sensoriamento remoto é o SEBAL (Surface Energy Balance Algorithm for Land), proposto por Bastiaanssen (1995), que tem obtido boa acurácia em diferentes aplicações (BASTIAANSSEN et al., 2000; BASTIAANSSEN et al., 2005; ALLEN et al., 2007; JIN et al., 2011; GUSMÃO et al., 2012), e tem viabilidade econômica por usar imagens de satélite e dados de superfície (BASTIAANSSEN et al., 2005; ALLEN et al., 2007). A determinação do balanço de energia pelo SEBAL envolve: (i) quantificar a energia líquida (Rn) dos fluxos das radiações de onda curta e de onda longa recebida e emitida pela superfície; e 
(ii) estimar os fluxos calor sensível (H), calor latente (LE) e calor no solo de utilização da radiação líquida disponível na superfície terrestre (LIU, 2007).

Além do conhecimento de Rn, o SEBAL ainda tem como produtos índices de vegetação (NDVI e SAVI), índice de área foliar, albedo e temperatura radiométrica da superfície que contribui para análises espaciais e temporais das mudanças na cobertura do solo devido a perturbações naturais ou antrópicas. Dada a importância do saldo de radiação da superfície e a falta de conhecimento de sua distribuição espacial e temporal em áreas naturais e manejadas no sudoeste da Amazônia Brasileira, o objetivo desse estudo foi avaliar a distribuição espacial e temporal de estimativas de Rn e parâmetros biofísicos por sensoriamento remoto em diferentes usos do solo no sudoeste da Amazônia Brasileira.
Humaitá, Amazonas, às margens da BR 319 sentido Humaitá-Manaus (Figura 1). A região é formada por aluviões do Holoceno com solos do tipo Argissolos, Cambissolos e Gleissolos que variam em função do relevo (SIBCS, 2009; CAMPOS et al., 2012). A topografia da região de estudo é plana, com áreas isoladas de relevo suave-ondulado. A vegetação é a de contato de campos com florestas, com várias formações campestres (BRAUN \& RAMOS, 1959). O clima é do tipo tropical chuvoso (Am segundo classificação de Köppen), com chuvas tipo monção e período seco de pequena duração. A temperatura média anual é de $25 \mathrm{a} 27^{\circ} \mathrm{C}$. O período chuvoso ocorre de outubro até junho, com média de precipitação anual de $2.500 \mathrm{~mm}$. A umidade relativa do ar varia de 85 a $90 \%$.

\section{MATERIAL E MÉTODOS}

\section{Área de Estudo}

A área de estudo está localizada na Fazenda Vanazzi $\left(7^{\circ} 35^{\prime} 43.34\right.$ " S e $63^{\circ} 6^{\prime} 50.71$ ” W) em

Figura 01. Localização e dimensões relativas das áreas de estudo no início do período seco de Humaitá, Amazonas.

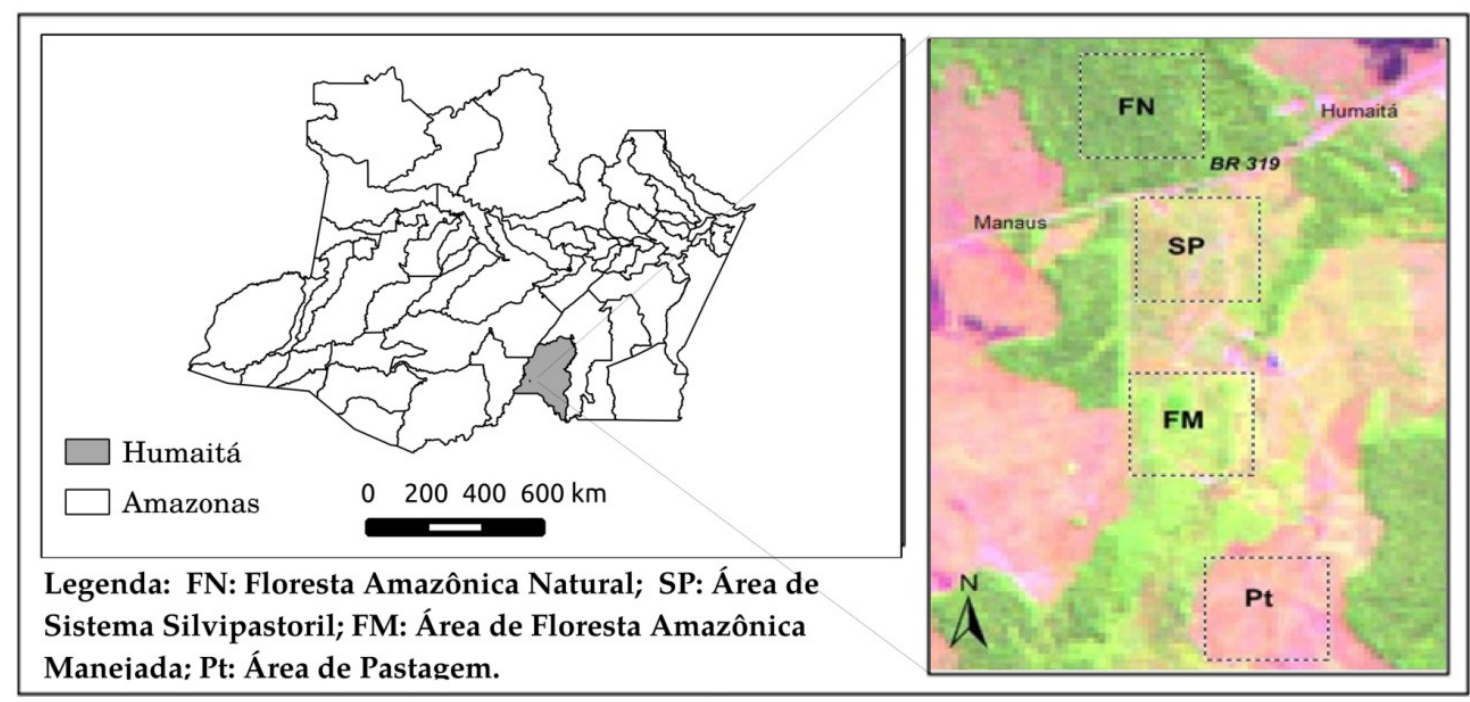

Fonte: Org. do autor 


\section{Medidas Meteorológicas}

Os dados micrometeorológicos descritos
Meteorologia (INMET) cuja estação está localizada em Humaitá/AM.

na Tabela 1 foram obtidos no Instituto Nacional de

Tabela 01- Dados de elevação solar, distância Terra-Sol (dr), cosseno do ângulo zenital (Z), umidade relativa (UR), temperatura da superfície (Tsuperf), pressão atmosférica (po), radiação solar incidente (Rsol_inc), radiação de onda longa emitida (Rol), e transmissividade atmosférica $\left(\mathrm{t}_{\mathrm{sw}}\right)$ no momento da passagem do satélite no sudoeste da Amazônica Brasileira.

\begin{tabular}{cccccccccc}
\hline Ano & $\begin{array}{c}\text { Elevação } \\
\text { do Sol }\end{array}$ & $\mathrm{d}_{\mathrm{r}}$ & $\cos (\mathrm{Z})$ & $\begin{array}{c}\mathrm{UR} \\
(\%)\end{array}$ & $\begin{array}{c}\mathrm{T}_{\text {superf }} \\
\left({ }^{\circ} \mathrm{C}\right)\end{array}$ & $\mathrm{p}_{\mathrm{o}}$ & $\mathrm{R}_{\text {sol_inc }}$ & $\mathrm{R}_{\mathrm{ol}}$ & $\mathrm{t}_{\text {sw }}$ \\
\hline $15 / 07 / 2009$ & 47,6622 & 0,9679 & 0,7392 & 63,50 & 29,60 & 99,90 & 683,60 & 395,20 & 0,707 \\
$02 / 07 / 2010$ & 47,3334 & 0,9670 & 0,7353 & 5,00 & 31,10 & 99,90 & 685,30 & 396,90 & 0,712 \\
$05 / 07 / 2011$ & 47,1539 & 0,9671 & 0,7332 & 65,00 & 24,55 & 99,90 & 690,40 & 357,30 & 0,719 \\
\hline
\end{tabular}

Fonte: Org. do autor

\section{Dados Orbitais}

Foram utilizadas imagens do sensor Thematic Mapper (TM) do satélite Landsat 5 da órbita 232 e ponto 65 fornecidas pelo Instituto Nacional de Pesquisas Espaciais (INPE). As imagens utilizadas foram dos dias 15/07/2009, 02/07/2010 e 05/07/2011 que correspondem ao período seco da região. As quatro áreas selecionadas para estudo foram: floresta amazônica natural (FN), sistema silvipastoril (SP), floresta amazônica manejada (FM), e pastagem (Pt). Cada área de 43,61 ha (484 pixels) foi localizada com GPS Garmin II (Figura 1, Tabela 2).

\section{Parâmetros de superfície estimados pelo algoritmo $S E B A L$}

As estimativas de Rn e parâmetros biofísicos pelo SEBAL seguiram diversas etapas de préprocessamento e processamento das imagens. O préprocessamento das imagens consistiu em (i) recortar as imagens obtidas do TM Landsat 5 da área estudo, (ii) empilhar as diversas camadas da imagem em um único arquivo de imagem, e (iii) ortorretificar e georreferenciar usando o sistema WGS84 (World Geodetic System 84) como padrão. 
Estimativa do balanço de radiação por sensoriamento remoto de diferentes usos de solo no sudoeste da Amazônia brasileira

Luiz Carlos Silva, José Maurício Cunha, Nadja Gomes Machado, Milton César Costa Campos, Marcelo Sacardi Biudes

Tabela 02. Localização e descrição das áreas de floresta amazônica natural (FN), sistema silvipastoril (SP), floresta amazônica manejada (FM), e pastagem (Pt) no sudoeste da Amazônia Brasileira. CSE = canto superior esquerdo. $\mathrm{CID}=$ canto inferior direito.

\begin{tabular}{|c|c|c|c|c|}
\hline Sigla & Área & CSE & CID & Descrição \\
\hline CN & floresta amazônica & $7^{\circ} 29^{\prime} 10^{\prime \prime} \mathrm{S}$ & $7^{\circ} 34^{\prime} 26^{\prime \prime} \mathrm{S}$ & Área utilizada para treinamento de soldados do \\
\hline FN & natural & $63^{\circ} 07^{\prime} 13^{\prime} \mathrm{W}$ & $63^{\circ} 06^{\prime} 53^{\prime \prime} \mathrm{W}$ & exército brasileiro \\
\hline FM & $\begin{array}{c}\text { floresta amazônica } \\
\text { manejada }\end{array}$ & $\begin{array}{c}7^{\circ} 35^{\prime} 099^{\prime \prime} \mathrm{S} \\
63^{\circ} 05^{\prime} 31^{\prime \prime} \mathrm{W}\end{array}$ & $\begin{array}{l}7^{\circ} 35^{\prime} 30^{\prime}, \mathrm{S} \\
63^{\circ} 06^{\prime} 45^{\prime}, \mathrm{W}\end{array}$ & $\begin{array}{c}\text { Área de extração de produtos florestais madeireiros } \\
\text { e não-madeireiros (palmitos e frutos de pupunha e } \\
\text { açaí nativos) }\end{array}$ \\
\hline SP & sistema silvipastoril & $\begin{array}{c}7^{\circ} 34^{\prime} 36^{\prime} \mathrm{S}^{\prime} \\
63^{\circ} 07^{\prime} 05^{\prime} \mathrm{W}\end{array}$ & $\begin{array}{c}7^{\circ} 34^{\prime} 57^{\prime \prime} \mathrm{S} \\
63^{\circ} 06^{\prime} 45^{\prime} \mathrm{W}\end{array}$ & $\begin{array}{c}\text { Sistema implantado em } 2004 \text { para cultivo de } \\
\text { Teca (Tectona grandis L.), Mogno (Swietenia } \\
\text { macrophylla King.), Andiroba (Carapa guianensis } \\
\text { Aubl.), Jenipapo (Genipa americana L.), e } \\
\text { pastagem de Brachiaria brizantha (cv. marandu) } \\
\text { nas entrelinhas destas espécies }\end{array}$ \\
\hline $\mathrm{Pt}$ & $\begin{array}{c}\text { pastagem } \\
\text { (Brachiaria } \\
\text { brizantha cv. } \\
\text { Marandu) }\end{array}$ & $\begin{array}{c}7^{\circ} 35^{\prime} 43^{\prime}, \mathrm{S} \\
63^{\circ} 06^{\prime} 53^{\prime \prime} \mathrm{W}\end{array}$ & $\begin{array}{c}7^{\circ} 34^{\prime} 57^{\prime} \mathrm{S} \\
63^{\circ} 06^{\prime} 45^{\prime} \mathrm{W}\end{array}$ & $\begin{array}{c}\text { Área com baixa produção de biomassa no } \\
\text { período chuvoso e baixa quantidade de biomassa } \\
\text { remanescente no período seco }\end{array}$ \\
\hline
\end{tabular}

Fonte: Org. do autor

O processamento da imagem consistiu em (i) converter os dados da imagem de números digitais para radiância espectral, (ii) obter a refletância e os índices SAVI (Soil-adjusted Vegetation Index) e de área foliar (IAF), (iii) estimar o albedo planetário e o albedo da superfície $(\alpha$ ), (iv) obter o NDVI (Normalized Difference Vegetation Index); (v) estimar a radiação de onda longa emitida pela superfície e pela atmosfera e da temperatura radiométrica da superfície (Ts); e (vi) estimativa do saldo de radiação. $\mathrm{O}$ detalhamento dos cálculos de Rn e dos parâmetros biofísicos pelo SEBAL estão descritos em (BEZERRA et al., 2014; LOPES et al., 2014; MACHADO et al., 2014; SALLO et al., 2014).

Mapas temáticos de NDVI, IAF, $\alpha$, Rn e Ts a partir das estimativas do SEBAL foram gerados no programa Surfer 8 com o objetivo de melhor ilustrar a distribuição espacial e temporal destas variáveis na área de estudo. Como a área $\mathrm{FN}$ não sofreu intervenção humana, ela foi escolhida como uma área em que processos biofísicos ocorrem em condições naturais e/ou ideais, isto é, sem conversão de vegetação nativa em outros tipos de usos do solo.

\section{RESULTADOS E DISCUSSÃO}

\section{NDVI}

Os valores mínimos $(0,61$ a 0,64$)$ e máximos $(0,74$ a 0,79$)$ de NDVI de FN geram sua variação espacial ilustrada na Figura 2 (i). A baixa amplitude de valores não influencia os valores médios observados de 0,70 a 0,72 , ratificando-os como representativos da área nos anos de 2009 a 2011. Estes valores são semelhantes aos de Gomes et al. (2013) para superfícies vegetadas. Os valores modais mostraram tendência de aumento de $0,695 \mathrm{em} 2009$ para 0,725 em 2011 e baixos desvios nos anos estudados.

Estes valores, se comparados à FM Figura 2 (ii) -, são altos, mas, não denotam ampla variação entre mínimos $(0,36$ a 0,44$)$, máximos $(0,80$ a 0,82$)$, médios $(0,68$ a 0,69$)$ e modais $(0,69$ a 0,72$)$ no período. São semelhantes aos verificados por Gomes et al. (2013), entretanto, os desvios são maiores desvios quando comparados com a FN. Este resultado pode ser explicado pelo manejo impingido à área, com retiradas periódicas de madeira que, para sua execução, exige abertura de caminhos e 
clareiras na floresta, tornando-a mais escassa em sítios específicos. Gomes et al. (2013) verificou valores de NDVI semelhantes aos aqui verificados quando avaliaram um manguezal que, à semelhança desta FM, possui grandes "espaçamentos” no dossel de árvores.

Figura 02. NDVI de (i) Floresta Amazônica Natural; (ii) Floresta Amazônica Manejada; (iii) Sistema Silvipastoril, e; (iv) Pastagem de Brachiaria brizantha.

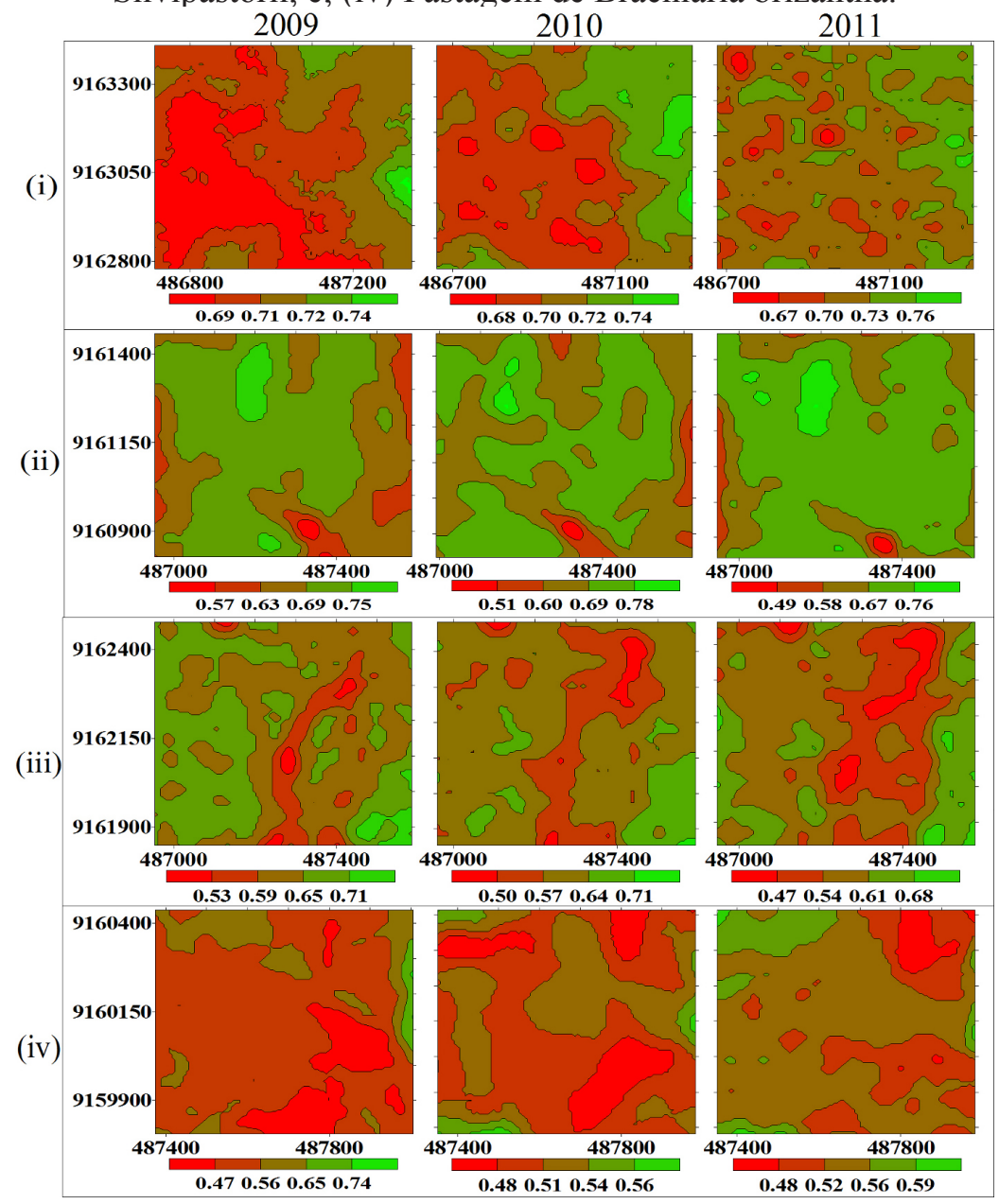

Fonte: Org. do autor

Os valores mínimos de 0,41 a 0,45 e máximos de 0,73 a 0,76 de NDVI do SP bem como a pequena variação espacial e temporal de 2009 a 2011 são ilustrados na Figura 2 (iii). Os valores médios $(0,57$ a 0,64$)$ e modais $(0,57$ a 0,63$)$ diminuíram do $1^{\circ}$ ao $3^{\circ}$ ano e são caracteristicamente altos, denotando cobertura satisfatória do solo pela vegetação. Pode existir relação entre o manejo característico de plantações mistas de árvores e forrageiras que, por ser de caráter econômico, exigem retiradas periódicas de madeira e pastejo do gado nas entrelinhas cobertas por pastagem, tornando-a mais rala. Este fato pode, mesmo assim, ratificar os resultados de Gomes et al. (2013) obtidos de superfície coberta com vegetação rala de meio urbano. Saliente-se que tais práticas podem explicar o desvio muito semelhante ao observado para FM entre 2009 e 2011. Ou seja, o padrão de cobertura do solo do SP mantém-se muito próximo ao da FM.

A variação anual e a semelhança de mínimos $(0,39$ a 0,44$)$ e máximos $(0,63$ a 0,80$)$ de NDVI de Pt - Figura 2 (iv) - de 2009 a 2011 também explicam seu desvio em relação às médias $(0,50$ a 0,53$)$ e modas $(0,50$ a 0,53$)$. Estes valores são inferiores tanto em 
relação ao SP, pois é característica da pastagem cobrir menos o solo devido ao menor porte e densidade da vegetação, quanto em relação às FN e FM.

As pastagens geralmente mostram menores valores de NDVI e IAF se comparados à vegetação fechada com maior porte das florestas. Os valores mínimos estimados referem-se a solo exposto e valores acima de 0,4 denotam raleamento severo da Pt enquanto que, mesmo em pleno período seco, valores de 0,5 a 0,6 podem indicar superfície relativamente bem coberta pela Pt. Este fato é explicado pelo maior aporte de umidade em função da precipitação acumulada no período de 30 dias antes do imageamento (Tabela 1), permitindo maior tempo de vegetação e acúmulo de biomassa pela pastagem (WATERLOO, 1994). Valores de NDVI menores que estes têm sido caracterizados como solo exposto por Gomes et al. (2013) ou áreas secas sem cobertura na superfície (RODRIGUES et al., 2009). De maneira geral, o pequeno decréscimo de NDVI em função do uso do solo segue um padrão, sendo maior para FN seguida da FM, SP e Pt.

\section{Índice de Área Foliar}

Em geral, verifica-se variação crescente de IAF, sendo os maiores valores observados para FN seguida da FM, SP e Pt. Os valores são considerados altos e todas as formas de uso do solo podem ser consideradas do ponto de vista ambiental, relativamente a outras formas de uso do solo na região, mantenedoras de sustentabilidade da propriedade uma vez que manter o solo coberto o ano inteiro significa minimizar efeitos de erosão e manter seu conteúdo de matéria orgânica (ALBUQUERQUE et al., 1995).

A variação espaço-temporal dos índices de área foliar (IAF) da FN encontra-se na Figura $3 i$. Estes valores, mostraram pequena variação de 2009 a 2011, tanto nos valores mínimos de 0,76 a 0,89 , quanto para os máximos de 1,48 a 1,55, relativamente entre 2009 e 2011. Tais observações são ratificadas pela similaridade entre médias $(1,04$ a 1,09) e modas $(1,01$ a 1,08$)$ e, consequentemente, os baixos desvios observados em todos os anos.

Estes valores modais ratificam a pequena variação de IAF de FN na imagem como um todo. Semelhantemente, Liberato (2011) utilizou-se do algoritmo SEBAL para uma estimativa não satisfatória de IAF máximo entre 1,54 e 1,57 $\mathrm{m}^{2}$ $\mathrm{m}^{-2}$ para floresta Amazônica no período seco. Estes valores são relativamente maiores que os máximos encontrados no presente estudo. Este fato corrobora a conjectura de que a metodologia possui limitação na determinação desta variável, ratificando os resultados de Biudes et al. (2014), cujo relato afirma que os IAF obtidos via imagens do satélite MODIS não correspondem à valores reais das variações sazonais e interanuais em florestas tropicais da Amazônia.

Uma análise comparativa dos IAF de FM - Figura 3 (ii) - com FN mostra maior variação de mínimos e máximos para esta última cobertura de solo. Os pequenos desvios de IAF de FM em relação à $\mathrm{FN}$ comprova esta verificação. A despeito da heterogeneidade da área de FM, as médias de IAF mostraram-se semelhantes entre si e maiores que os valores observados para $\mathrm{FN}$, isenta ação antrópica até a última data de imageamento em 2011.

Pode-se conjecturar que o manejo anual impingido à área para fornecimento de madeira para fins energéticos e construções, semelhantemente ao NDVI, pode explicar o fato. A derrubada de árvores da floresta forma clareiras (RUNKLE, 1990) e, consequentemente, surgem áreas de solo com menor cobertura vegetal. Tal configuração gera heterogeneidade e aumenta a amplitude dos valores mínimos e máximos e influencia a média de IAF que, enfim, pode não representar satisfatoriamente o que ocorre na FM. Este fato também explica os valores modais altos e semelhantes entre os anos avaliados. Provavelmente representam áreas que possuem mais vegetação cobrindo o solo em função do menor impacto do manejo inicial e retirada periódica de, principalmente, árvores inteiras da floresta. 
Figura 03. IAF de (i) Floresta Amazônica Natural; (ii) Floresta Amazônica Manejada; (iii) Sistema Silvipastoril, e; (iv) Pastagem (Brachiaria brizantha).

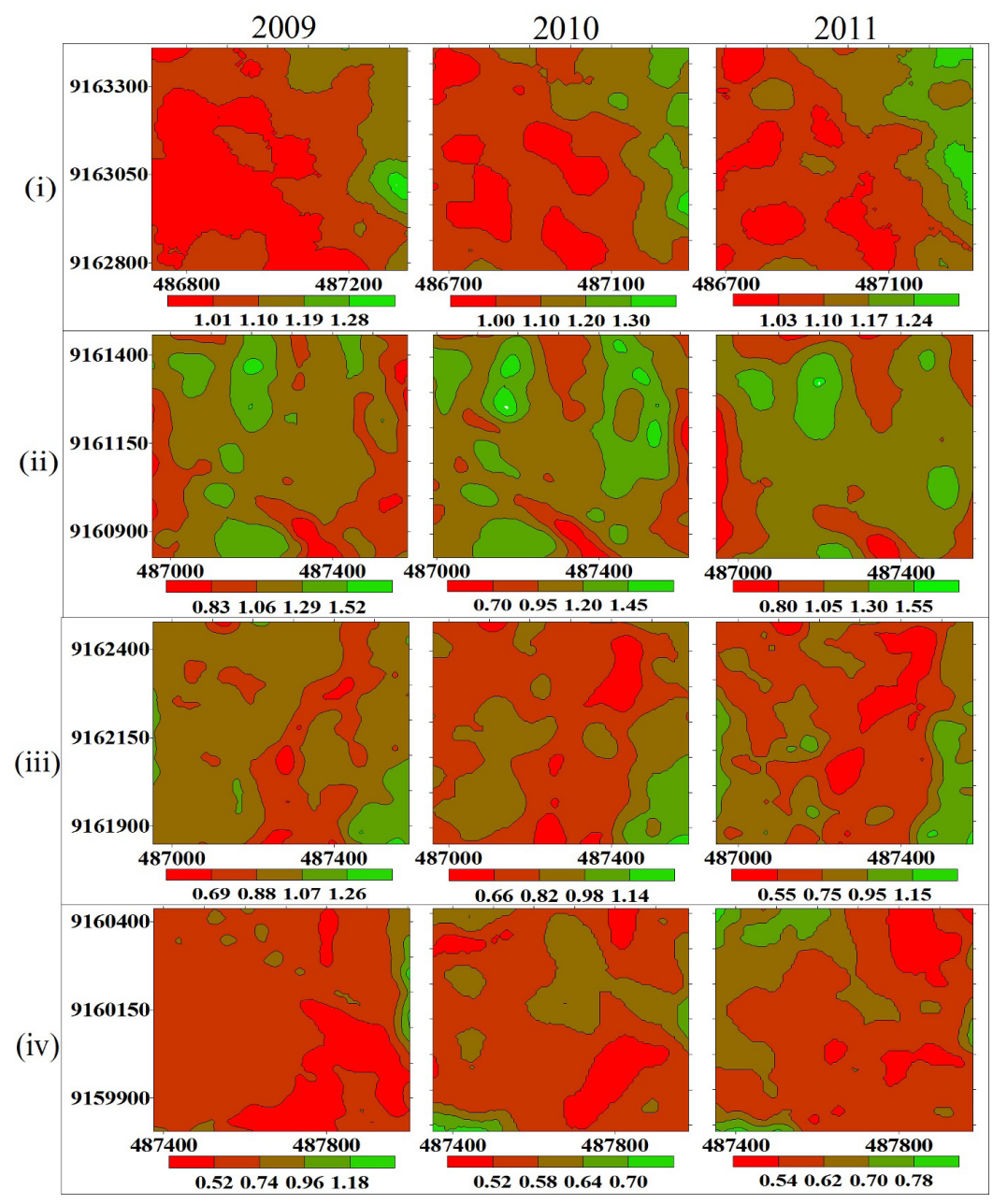

Fonte: Org. do autor

O SP, a exemplo da FM, apresentou maior variação relativa entre mínimos $(0,38$ a 0,48$)$ e máximos $(1,27$ a 1,41) de IAF, apresentando tendência de diminuição ao longo dos anos estudados - Figura 3 (iii). Os valores modais de 0,94 a 0,74 , e médios de 0,75 a 0,93 , cujos desvios são maiores que os demais usos do solo, assemelham-se entre si. Entretanto, mostraram-se inferiores aos valores observados para FN e FM. Pode-se conjecturar que isso se deve às características intrínsecas do sistema, que agrupa diversas espécies arbóreas, plantadas com amplo espaçamento entre linhas, e pastagem cultivada na entrelinha. Essa configuração gera heterogeneidade nos valores de IAF, que estão abaixo de 1,56 a 1,97 encontrados por Liberato (2011) para áreas agrícolas que apresentam cobertura de solo similares ao SP praticado na Amazônia.

A - Figura 3 (iv) - ilustra constatações feitas para a área de pastagem de Brachiaria brizantha (cv. marandu) (Pt). Saliente-se que houve grande variação de IAF mínimos $(0,32$ a 0,43$)$ e máximos (0,95 a 1.37) de 2009 a 2011. Os valores máximos mostraram ligeira diminuição do $1^{\circ}$ para o $3^{\circ}$ ano, o que concorda com Liberato (2011) que encontrou valores comuns máximos de IAF entre 1,56 e 1,97 para pastagens na Amazônia. No entanto, encontramse abaixo das constatações de campo feitas por Zanchi et al. (2009), que obtiveram valores de IAF de até 
2,0 $\mathrm{m}^{2} \mathrm{~m}^{-2}$ para pastagem em Rondônia. Os valores médios e modais de IAF estiveram cerca de 10 a $15 \%$ menores que os valores verificados para o SP, e 40 a $50 \%$ menores que as observações feitas para a FN e FM de 2009 a 2011. A Brachiaria brizantha, em função de seu crescimento cespitoso e entouceirado, cobre menos o solo e influencia o IAF, reduzindo seu valor. Este fato pode ainda ser explicado pelo seu estado de degradação, característico das pastagens do sul do Amazonas.

Saliente-se que as médias de IAF de todas as formas de cobertura do solo concordam com verificações de Zanchi et al. (2009) e Liberato (2011), evidenciando que as variações de IAF devem-se às características intrínsecas de cada cobertura e à pluviosidade no período estudado. Adicionalmente, some as interações das diferentes coberturas com as variáveis microclimáticas, o que é assunto ainda a ser mais estudado deste ponto de vista específico. Este fato é ratificado por Biudes et al. (2014) que demonstraram, por medições in loco, que diferentes ecossistemas que cobrem o solo apresentam diferentes variações sazonais nos valores de IAF. Além disso, a pastagem e o SP foram calcariados e fertilizados a um intervalo maior que 10 anos. E isso pode aumentado a disponibilidade e absorção de nutrientes do solo (MALAVOLTA, 2006), proporcionando maior produção de biomassa pela vegetação das coberturas que, previamente, já possuem área fotossintética maior, caso da FN, FM e SP.

Também é fato que os IAF estão vinculados ao crescimento em área foliar e desenvolvimento vegetal (ESTEVES et al., 2012) que, por sua vez, é dependente da disponibilidade de nutrientes (LARCHER, 2007) mesmo que em baixas concentrações no solo. Solos sob pastagem na Amazônia apresentam geralmente baixa fertilidade (SALIMON et al., 2007) e o mesmo ocorre com solos que suportam campos naturais onde predominam gramíneas (CAMPOS et al., 2012). Este fato reflete-se em baixa produção de biomassa na estação chuvosa e, consequentemente, menores valores de IAF são verificados. No entanto, forrageiras que fixam $\mathrm{CO}_{2}$ pela via $\mathrm{C}_{4}$, como as braquiárias, são menos exigentes em fertilidade do solo (MALAVOLTA, 2006) em relação a outras espécies. Esta mesma afirmação poder ser aplicada para as essências florestais de ciclo $\mathrm{C}_{3}$, que compõem o SP estudado.

As médias de $\operatorname{IAF}(0,51$ a 0,61$)$ de $\mathrm{Pt}$ foram semelhantes no período avaliado. Porém, os valores aumentam da Pt para SP e deste para FM, decaindo na FN. Saliente-se que o IAF médio de FM é provindo de uma amplitude maior de valores mínimos e máximos, o que se deve ao manejo anual impingido à área. Consequentemente, esta média pode não ter sido representativa, pois, mínimos e máximos são determinados por sítios específicos da área mais ou menos afetados pelo manejo. Como os IAF foram muito semelhantes aos do SP, tal argumentação também serve para esta cobertura de solo. De maneira geral, os IAF médios mostraram tendência de diminuição da FN para FM e deste para SP e Pt.

\section{Albedo}

A Figura 4 (i) ilustra a variação dos valores mínimos $(0,09$ a 0,10$)$ e máximos $(0,14$ a 0,15$)$ de $\alpha$ da superfície de FN no período estudado. Estes valores são comparativamente menores à $\mathrm{FM}, \mathrm{SP}$ e Pt. Uma pequena variação espacial pode ser ratificada pela análise das médias $(0,11$ a 0,15$)$ e modais $(0,11$ a 0,12$)$ e seu baixo desvio relativo. Este fato denota existência de homogeneidade de cobertura do solo da área de FN em relação às demais coberturas de solo. De modo geral são valores que conferem com os resultados de literatura e por ela foram ratificados em campo (LIBERATO, 2011; ZANCHI et al., 2009) a despeito da alta precipitação acumulada e elevada umidade relativa do ar no período anterior e no dia do imageamento (Tabela 1), que podem ter influenciado os resultados. 
Figura 04. Albedo de (i) Floresta Amazônica Natural; (ii) Floresta Amazônica Manejada; (iii) Sistema Silvipastoril, e; (iv) Pastagem (Brachiaria brizantha).

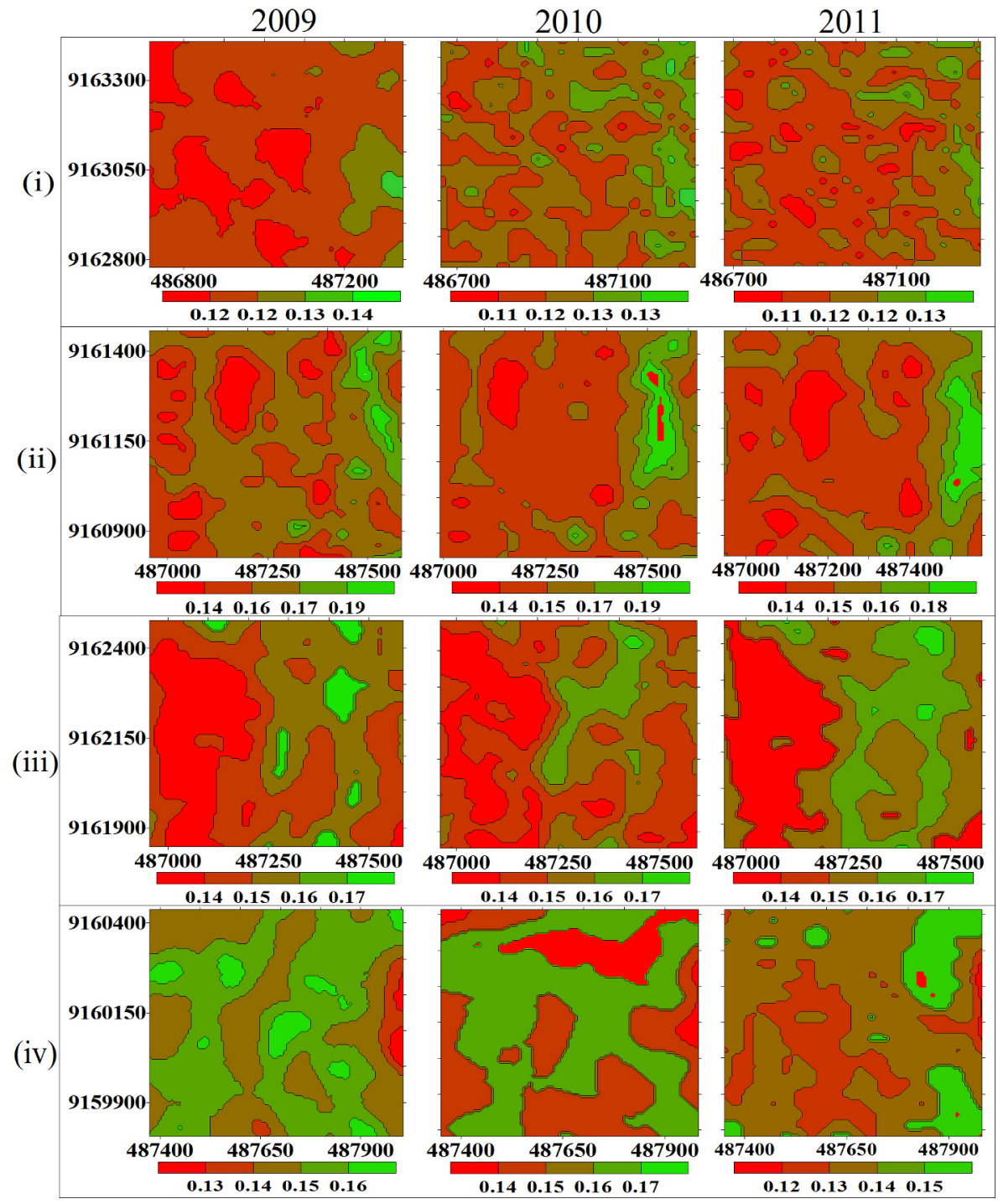

Org. do autor

O $\alpha$ do SP mostrou-se constante de 2009 $(0,152)$ a $2011(0,150)$. As figuras 4ii, 4iii e 4ivilustram pequena variação do $\alpha$ das áreas com mais vegetação (FN, FM e SP), fato que é corroborado pela variação semelhante de IAF de todas as coberturas do solo. André et al. (2010) relataram aumento no $\alpha$ em função do aumento da biomassa produzida e maior cobertura do solo. Os valores de $\alpha$ da FM foram maiores que na $\mathrm{FN}$, mostrando variação de 0,13 a 0,19 enquanto que na Pt variaram de 0,11 a 0,16 . Oguntunde et al. (2006) verificaram oscilação de 0,28 a 0,29 para solos descobertos, evidenciando que, neste estudo, a biomassa da Pt cobre satisfatoriamente o solo a ponto de reduzir os valores de $\alpha$. Estes valores também são corroborados por Gomes et al. (2013), e indicam não ocorrência de mudanças drásticas nas superfícies de 2009 a 2011 em função do $\alpha$, como igualmente relatado por Silva et al. (2005).

Segundo Oguntunde et al. (2006) variações de 0,100 a 0,150 no $\alpha$ são características de áreas vegetadas, tanto em estimativas via imagens de satélite (RODRIGUES et al., 2009; GOMES et al., 2013) quanto em mensurações em campo (LEIVAS et al., 2007; GOMES et al., 2013). Saliente-se que 
estas refletividades, à semelhança das observações de Gomes et al. (2013), são menores que os valores medidos em campo por Esteves et al. (2012). Lima et al. (2009) também averiguou em pastagem do semiárido, no período seco, resultados semelhantes a estes, ratificando a influência da umidade do ar e solo (WANG \& DAVIDSON, 2007) proporcionada pelas chuvas em período imediatamente anterior ao imageamento.

\section{Temperatura de Superfície}

As pequenas variações espaciais e temporais de temperatura de superfície (Ts) das formas de uso do solo estudadas estão ilustradas na Figura 5.
Este fato pode ser explicado pelo grande volume de vegetação de porte arbóreo que persiste tanto na FN quanto na FM. O comportamento semelhante para o SP e pastagem pode ser explicado pela manutenção e até aumento da produção de biomassa na superfície proporcionada por práticas como a fertilização e calcariação feita cercam alguns anos antes $1^{\circ}$ ano de imageamento (2009). Estas práticas podem ter conduzido tanto o SP quanto à $\mathrm{Pt}$ a uma maior produção de biomassa que, ao final do período chuvoso, ainda verdeja e permanece cobrindo o solo permitindo, por isso, maior controle da variação da temperatura da superfície.

Figura 05. Temperatura da superfície de (i) Floresta Amazônica Natural; (ii) Floresta Amazônica Manejada; (iii) Sistema Silvipastoril, e; (iv) Pastagem (Brachiaria brizantha).

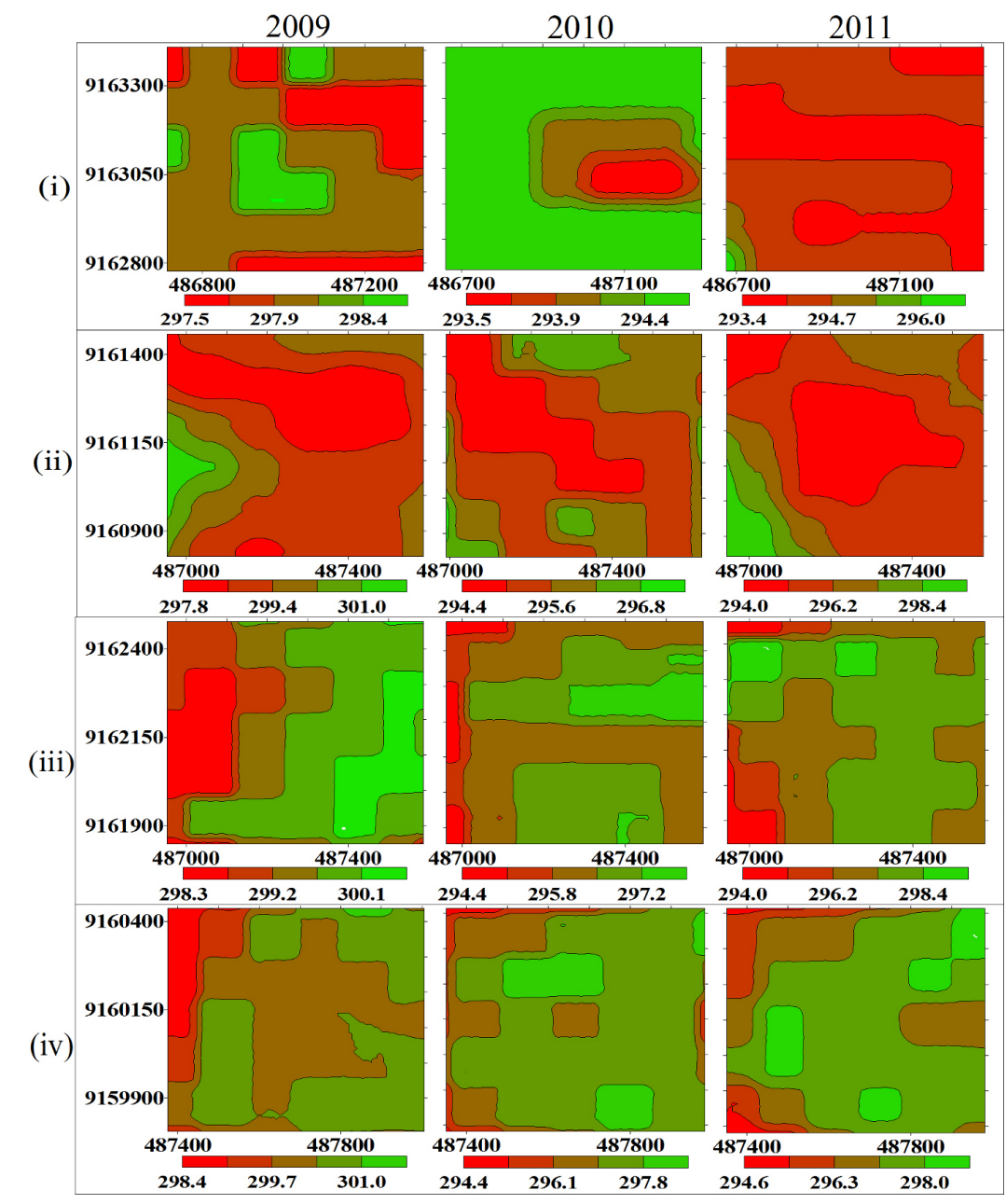

Fonte: Org. do autor 
A boa disponibilidade de água no solo em função da precipitação acumulada no período anterior ao imageamento (Tabela 1) nos três anos também pode ter corroborado com estas observações e proporcionado maior período de vegetação e acumulo biomassa tanto pelas FN e FM quanto para SP e Pt. Este acúmulo de biomassa, especialmente da Pt, foi suficiente para alimentar o gado na estação chuvosa e cobrir satisfatoriamente o solo no início do período seco da região, mantendo o padrão de temperatura à superfície semelhante às demais formas de uso do solo. Estes resultados são muito semelhantes aos obtidos por Gomes et al. (2013), que atribuíram esta classificação mediana a valores de temperaturas próximas de $300 \mathrm{~K}$ para áreas de mata ciliar e áreas com apenas resquícios de vegetação cobrindo solos urbanos.

\section{Saldo de Radiação}

Não foram observadas grandes variações nos mínimos (480,6 W m² em 2011) e máximos $(592,3$ $\mathrm{W} \mathrm{m}^{-2}$ em 2010) do Rn para todas as coberturas de solo no início do período seco do período estudado. Tais resultados devem-se à menor umidade relativa do ar no dia de imageamento deste ano (Tabela 1). Em consonância com valores de $\alpha$ (SILVA et al. 2009; GOMES et al. 2013), o Rn de FN mostrou valores mínimos $\left(531,2\right.$ a $\left.556,7 \mathrm{~W} \mathrm{~m}^{-2}\right)$, máximos $(563,1$ a $\left.592,3 \mathrm{~W} \mathrm{~m}^{-2}\right)$ e médios $\left(552,8\right.$ a $\left.576,4 \mathrm{~W} \mathrm{~m}^{-2}\right)$ maiores que as demais coberturas de solo no período (Figura $6)$.

Figura 06. Saldo de Radiação Instantâneo de (i) Floresta Amazônica Natural; (ii) Floresta Amazônica Manejada; (iii) Sistema Silvipastoril, e; (iv) Pastagem (Brachiaria brizantha).

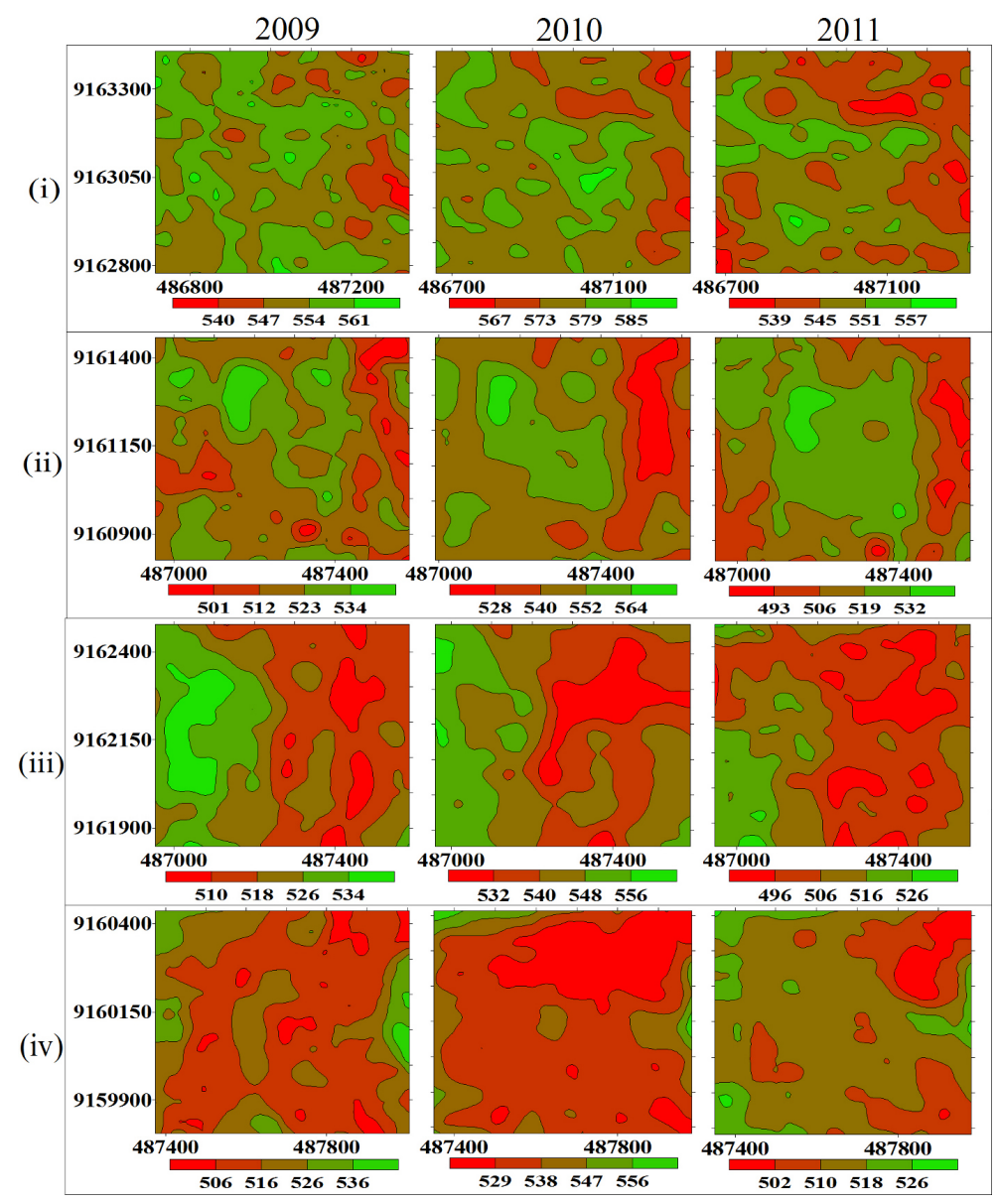

Fonte: Org. do autor 
As médias de Rn seguem a tendência de diminuição em função da cobertura do solo sendo maiores para FN, seguida pela FM, SP e Pt, exatamente ao contrário do ocorrido com o $\alpha$ das superfícies, que mostrou tendência à diminuição. Em 2010, a média de Rn mostrou-se maior para todas as coberturas de solo, o que pode ser explicado pela baixa umidade relativa do ar média, além da água ainda presente no solo em função da precipitação acumulada no período anterior imageamento (Tabela 1). Mais água disponível significa maior transpiração e aumento desta variável (GOMES et al., 2013), o que ocorre em função do uso de mais energia radiativa neste processo.

Florestas densas absorvem mais radiação que áreas desmatadas e pastagens, corroborando com estes resultados que se assemelham aos de Bezerra et al. (2008) e Gomes et al. (2013). Rodrigues et al. (2009) e Di Pace et al. (2008) também validaram, em superfície, altos valores de Rn para solo coberto com vegetação mais densa e valores menores para solo exposto de meio urbano e semiárido nordestino. Resultados de Liberato (2011) e Zanchi et al. (2009) obtidos em superfícies de floresta, pastagem e outros sistemas agrícolas na Amazônia foram semelhantes a estes e também corroboram com os deste trabalho.

\section{CONCLUSÕES}

1. O NDVI, IAF e albedo diminuíram da floresta natural para floresta manejada, sistema silvipastoril e pastagem;

2. A temperatura de superfície apresentou pequena amplitude entre a área com maior e menor densidade de vegetação, mas aumentou da floresta natural com maior biomassa, para a pastagem que tem menor biomassa;

3. O saldo de radiação, que é o resultado da integração entre todas as demais variáveis analisadas nesse trabalho, foi maior na floresta natural, seguido pela floresta manejada, sistema silvipastoril e pastagem. Isso indica que o desmatamento da Floresta Amazônica tem a capacidade de alterar a capacidade da superfície em reter energia para ser os processos de evapotranspiração e para o aquecimento do ar e do solo. Como consequência, pode modificar o clima de toda a região.

\section{AGRADECIMENTOS}

Ao Instituto Nacional de Meteorologia (INMET) por ceder os dados meteorológicos e ao Instituto de Pesquisas Espaciais (INPE) por disponibilizarem as imagens de satélites.

\section{REFERÊNCIAS}

ALBUQUERQUE, J. A.; REINERT, D. J.; FIORIN, J. E.; RUEDELL, J.; PETRERE, C.; FONTINELLI, F. Rotação de culturas e sistemas de manejo do solo: efeito sobre a forma da estrutura do solo ao final de sete anos. Revista Brasileira de Ciência de Solo, v. 19, n. 1, p. 115-119, 1995.

ALLEN, R.; IRMAK, A.; TREZZA, R.; HENDRICKX, J.M.H.; BASTIAANSSEN, W.; KJAERSGAARD, J. Satellite-based ET estimation in agriculture using SEBAL and METRIC. Hydrological Processes, v. 25, p. 4011-4027, 2011. DOI: 10.1002/hyp.8408

ALLEN, R.; TASUMI, M.; TREZZA, R. SatelliteBased Energy Balance for Mapping Evapotranspiration with Internalized Calibration (METRIC)-Model. Journal of Irrigation and Drainage Engineering, v. 133, n. 4, p. 380-394, 2007.

ANDRÉ, R.G.B; MENDONÇA, J.C.; PINHEIRO, F.M.A.; MARQUES, V. S.; MARQUES, J. Aspectos energéticos do desenvolvimento da cana-de-açúcar Parte 1: Balanço de radiação e parâmetros derivados. Revista Brasileira de Meteorologia, v. 25, n. 3, p. 375-382, 2010. DOI: http://dx.doi.org/10.1590/S010277862010000300009

BASTIAANSSEN, W. G. M. SEBAL-based sensible and latent heat fluxes in the irrigated Gediz Basin, Turkey. Journal of Hydrology, v. 229, p. 87-100, 2000. DOI: 10.1016/S0022-1694(99)00202-4

BASTIAANSSEN, W. G. M.; NOORDMAN, E. J. M.; PELGRUM, H.; DAVIDS, G.; THORESON, B. P.; ALLEN, R. G. SEBAL Model with Remotely Sensed 
Data to Improve Water-Resources Management under Actual Field Conditions. Journal of Irrigation and Drainage Engineering, v. 131, n. 1, p. 85-93, 2005. DOI: 10.1061/(ASCE)0733-9437(2005)131:1(85)

BASTIAANSSEN, W.G.M. Regionalization of surface flux densities and moisture indicators in composite terrain: A remote sensing approach under clear skies in Mediterranean climate. Netherlands: CIP Data Koninklijke Biblioteheek, Den Haag. Tese de Doutorado. 1995, 272p.

BASTIAANSSEN, W.G.M., MENENTI, M.; FEDDES, R.A.; HOLTSLAG, A.A.M. A remote sensing surface energy balance algorithm for land (SEBAL). Part. 1: Formulation. Journal of Hydrology, v. 212-213, p. 198-212, 1998. DOI:10.1016/S00221694(98)00253-4

BEZERRA, B. G.; SILVA, B. B.; FERREIRA, N. J. Estimativa da evapotranspiração real diária utilizandose imagens digitais TM - Landsat 5. Revista Brasileira de Meteorologia, v. 3, p. 305-317, 2008. DOI: http:// dx.doi.org/10.1590/S0102-77862008000300005

BEZERRA, J. M.; MOURA, G. B. A.; SILVA, B. B.; LOPES, P. M. O.; SILVA, Ê. F. F. Parâmetros biofísicos obtidos por sensoriamento remoto em região semiárida do estado do Rio Grande do Norte, Brasil. Revista Brasileira de Engenharia Agrícola e Ambiental, v. 18, n. 1, p. 73-84, 2014.

BIUDES, M.S.; MACHADO, N.G.; DANELICHEN, V.H.M.; SOUZA. M.C.; VOURLITIS, G.L.; NOGUEIRA, J. S. Ground and remote sensing-based measurements of leaf area index in a transitional forest and seasonal flooded forest in Brazil. International Journal of Biometeorology, v. 58, n. 6, p. 1181-1193, 2014.

BRAGA, C.C.; SOARES, F.R.; DANTAS, F.R.C.; BARBIERI, L.F.P. Determinação do albedo e índice de área foliar usando o sensor TM / LANDSAT 5. Anais XIV Simpósio Brasileiro de Sensoriamento Remoto, Natal, Brasil, 25-30 abril 2009, INPE, p. 935-942.
BRAUN, E. H. G.; RAMOS, J. R. A. Estudo agroecológico dos campos Puciari-Humaitá (Estado do Amazonas e Território Federal de Rondônia). Revista Brasileira de Geografia, v.21, p.443-497, 1959.

CAMPOS, M. C. C.; RIBEIRO, M. R.; SOUZA JÚNIOR, V. S.; RIBEIRO FILHO, M. R.; ALMEIRA, M. C. Topossequência de solos na transição Campos Naturais-Floresta na região de Humaitá, Amazonas. Revista Acta amazônica, v. 42, n. 3, p. 387-398, 2012. DOI: 10.1590/S0044-59672012000300011

COURAULT, D.; SGUIN, B.; OLIOSO, A. Review on estimation of evapotranspiration from remote sensing data: from empirical to numerical modeling approaches. Irrigation and Drainage System, v.19, p. 223-249, 2005.

DI PACE, F. T. D.; SILVA, B. B.; SILVA, V. P. R.; SILVA, S. T. A. Mapeamento do saldo de radiação com imagens Landsat 5 e modelo de elevação digital. Revista Brasileira de Engenharia Agrícola e Ambiental, Campina Grande, v. 12, n. 4, p. 385392, 2008. DOI: http://dx.doi.org/10.1590/S141543662008000400009

ESTEVES, B.S.; SOUSA, E.F.; MENDONÇA, J. C.; LOUSADA, L.; MUNIZ, R.; SILVA, R.M. Variações do albedo, NDVI e SAVI durante um ciclo da canade-açúcar no Norte Fluminense. Revista Brasileira de Ciências Agrárias, v. 7, n. 4, p. 663-670, 2012. DOI:10.5039/agraria.v7i4a1597

GOMES, L.C.F., SANTOS, C.A.C., ALMEIDA, H.A. Balanço de Energia à Superfície para a Cidade de Patos-PB Usando Técnicas de Sensoriamento Remoto. Revista Brasileira de Geografia Física, v. 6, n. 1, p. 15-28, 2013.

GUSMÃO,A.C.V.L.; SILVA, B. B.; MONTENEGRO, S. M. G. L.; GALVÍNCIO, J. D. Determinação do saldo radiativo na Ilha do Bananal, TO, com imagens orbitais. Revista Brasileira de Engenharia Agrícola e Ambiental, v. 16, n. 10, p. 1107-1114, 2012. DOI: http://

Soc. \& Nat., Uberlândia, 27 (2): 341-356, mai/ago/2015 
Estimativa do balanço de radiação por sensoriamento remoto de diferentes usos de solo no sudoeste da Amazônia brasileira Luiz Carlos Silva, José Maurício Cunha, Nadja Gomes Machado, Milton César Costa Campos, Marcelo Sacardi Biudes

dx.doi.org/10.1590/S1415-43662012001000011

JIN, Y.; RANDERSON, J. T.; GOULDEN, M. L. Continental-scale net radiation and evapotranspiration estimated using MODIS satellite observations. Remote Sensing of Environment, v. 115, p. 2302-2319, 2011. DOI:10.1016/j.rse.2011.04.031

LARCHER, W. Ecofisiologia vegetal. São Carlos: Edit. Rima, 2006. 550 p.

LEIVAS, J.; GUSSO, A.; FONTANA, D. C. Estimativa do balanço de radiação na superfície a partir de imagens ASTER, IN Simpósio Brasileiro de Sensoriamento Remoto, Florianópolis, p. 255-262, 2007.

LIBERATO, A.M. Estimativa do albedo e índice de área foliar na Amazônia. Revista Brasileira de Geografia Física, v. 4, n. 1, p. 22-32, 2011.

LIMA, E. P.; ANDRADE, R. G.; SEDIYAMA, G. C.; DELGADO, R. C.; FERREIRA, A. S.; CAPUTI, E.; FERREIRA, W.J. Estudo da evapotranspiração real diária utilizando imagem de satélite na bacia do rio Paracatu. Anais II Seminário de Recursos Hídricos da Bacia Hidrográfica do Paraíba do Sul: Recuperação de Áreas Degradadas, Serviços Ambientais e Sustentabilidade, Taubaté, Brasil, IPABHi, p.1-8, 2009.

LIU, W.T.H. Aplicações de sensoriamento remoto. Campo Grande - MS, Ed. UNIDERP, 2007. 908 p.

LOPES, H. L.; SILVA, B. B.; PACHECO, A. P. Distribuição espacial do saldo de radiação e do fluxo de calor no solo no território de Itaparica, Nordeste do Brasil. Revista Brasileira de Cartografia, v. 66, n. 2, p. 233-244, 2014.

MACHADO, C.C.; SILVA, B.B.; DE ALBUQUERQUE, M. B.; GALVINCIO, J. D. Estimativa do balanço de energia utilizando imagens TM - Landsat 5 e o algoritmo SEBAL no litoral sul de Pernambuco. Revista Brasileira de Meteorologia, vol. 29, n. 1, p. 55-67, 2014. DOI: http://dx.doi. org/10.1590/S0102-77862014000100006
MALAVOLTA, E. Manual de nutrição mineral de plantas. São Paulo: Agronômica Ceres; 2006. 638p.

OGUNTUNDE, P. G.; AJAYI, A. E.; GIESEN, N. V. Tillage and surface moisture effects on baresoil albedo of a tropical loamysand. Soil and Tillage Research, v. 85 , n. $1-2$, p. $107-114,2006$. DOI:10.1016/j. still.2004.12.009

RODRIGUES, J. O.; ANDRADE, E. M.; TEIXEIRA, A. S.; SILVA, B. B. Sazonalidade de variáveis biofísicas em regiões semiáridas pelo emprego do sensoriamento remoto. Engenharia Agrícola, v. 29, n. 3 , p. $452-465,2009$. DOI: org/10.1590/S010069162009000300012

ROERINK, G.J.; SU, Z.; MENENTI, M. S - SEBI: A Simple Remote Sensing Algorithm to Estimate the Surface Energy Balance. Physical chemistry. Earth (B), v.25, n.2, p.147-157, 2000. DOI:10.1016/S14641909(99)00128-8

RUNKLE, J. R. Gap dynamics of Ohio-Fagus forest and speculations on the geography of disturbance. Canadian Journal of Forest Research, v. 20, p. 632642, 1990.

SALIMON, C. G. I.; WADT, P. G. S.; MELO, A. W. F. Dinâmica do carbono na conversão de floresta para pastagens em Argissolos da formação geológica Solimões, no sudoeste da Amazônia. Revista de Biologia e Ciências da Terra, v.7, n.1, 2007.

SALLO, F. S.; FRANÇA, M. S.; MORAIS, D. M.; RODRIGUES, R.; BIUDES, M. S. Estimativa de componentes do balanço de radiação em diferentes tipos de uso e cobertura do solo. Revista Ambiente \& Água, v. 9, n. 2, p. 347-358, 2014. DOI: http://dx.doi. org/10.4136/ambi-agua.1273.

SIBCS. Sistema brasileiro de classificação dos solos. Rio de Janeiro: Embrapa Solos, 2009. 397p.

SILVA, B. B.; LOPES, G. M.; AZEVEDO, P. V. Determinação do albedo em áreas irrigadas com base em imagens Landsat 5-TM; Revista Brasileira 
de Meteorologia, São José dos Campos, v.13, n.2, p.201-211, 2005.

SILVA, C. A. V.; SILVA, H. A.; OLIVEIRA, T. H.; GALVÍNCIO, J. D. Uso do Sensoriamento Remoto através de Índices de Vegetação NDVI, SAVI e IAF na microrregião de Itamaracá - PE. Anais XIV Simpósio Brasileiro de Sensoriamento Remoto, pp. 3079-3085, 2009.

WANG, S.; DAVIDSON, A. Impact of climate variations on surface albedo of a temperate grassland. Agricultural and Forest Meteorology, v. 142, p. 133142, 2007. DOI: 10.1016/j.agrformet.2006.03.027

WATERLOO, M. J. Water and nutrient dynamics of Pinus caribaea plantation forests on former grassland soils IN S.W.; Viti Levu, Fiji., Ph.D. thesis, Vrije Universiteit Amsterdam, The Netherlands, 1994. $478 \mathrm{p}$.

ZANCHI, F. B.; WATERLOO, M. J.; AGUIAR, L. J. G.; RANDOW, C. V.; KRUIJT, B.; CARDOSO, F. L.; MANZI, A. O. Estimativa do Índice de Área Foliar (IAF) e Biomassa em pastagem no estado de Rondônia, Brasil. Acta Amazonica, v. 39, n. 2, p. 335-348, 2009. DOI: http://dx.doi.org/10.1590/S004459672009000200012 